co-ordinates of stars in the $F K 3$ catalogue were adopted for time determination from January 1, 1940. The Union adopted the specification of the primary standard of wave-lengths formulated in 1935 by the International Committee of Weights and Measures, and adopted fresh secondary iron standards in the ultra-violet and solar standards in the infrared; it also agreed to a standard notation for describing lines. A special grant was made towards the expense of reproduction of the Utrecht photometric solar atlas giving the profiles of all Fraunhofer lines from Mount Wilson plates between 3300 and $8900 \mathrm{~A}$.

It was agreed to give presidents of commissions wider powers to form sub-commissions with the view especially of developing work in subjects bordering on the special work of two or more commissions, and an additional commission on inter-stellar matters was created.

An invitation to hold the next meeting in 1941 in Switzerland was accepted very cordially and the executive committee for the next three years was elected as follows : President : Sir Arthur Eddington (Great Britain); Vice-Presidents : Prof. G. Abetti (Italy), Dr. W. S. Adams (U.S.A.), Prof. O. Bergstrand (Sweden), Prof. W. Brunner (Switzerland) and Prof. Ch. Fabry (France); Secretary: Prof. J. H. Oort (Holland).

\title{
Humidity in the British Isles
}

$\mathrm{T}$ HE importance of humidity as a climatological element has been increasingly realized in recent years. Until quite recently, however, comparatively few summarized data were available for the use of industrial technologists, bioclimatologists and others to whom the humidity of the air in the British Isles is a matter of concern. There were, in fact, only two published collections of average values, W. F. Stacey's averages, with charts, for 91 stations in England and Wales" and Section 6 of "The Book of Normals" 2 containing hourly averages for five observatories, with isopleth diagrams of hourly averages for seven additional stations.

In both these publications, relative humidity was the only element treated. Stacey's averages were based on readings at $9 \mathrm{~h}$. during the ten years $1901-10$, and his stations were sufficiently numerous to give a fair representation of the average distribution of relative humidity over England and Wales at $9 \mathrm{~h}$. It is difficult, however, to draw any useful conclusions from charts and averages based on observations at $9 \mathrm{~h}$., an epoch at which relative humidity is normally in process of descending from the early morning maximum to the afternoon minimum. This limitation will be realized if one imagines how incomplete our information about air temperature would be if we had nothing beyond the readings of an ordinary thermometer at $9 \mathrm{~h}$.

Apart from relative humidity, there are at least two other hygrometric elements for which scarcely any summarized data have hitherto been available, namely, vapour pressure and moisture content. Averages for the principal observatories are given in Bilham's "Climate of the British Isles"3, but it is clearly desirable that values of these two important elements should be available for a large number of stations.

These needs have now been met by an official publication* recently issued. In view of the fact that the book contains an explanatory introduction, 21 pages of tabular matter and 26 charts, it may be described as extraordinarily good value for money. The main table contains monthly and annual averages for 44 synoptic stations, six columns of data being given for each station. The first four columns refer to $13 \mathrm{~h}$. and contain 15-year averages of air temperature, relative humidity, vapour pressure in millibars, and moisture content in grams per cubic metre. The remaining two columns contain averages of relative

" "Averages of Humidity for the British Isles". M.0. 421. (London : H.M. Stationery Office.) $9 d$. net. humidity at $7 \mathrm{~h}$. and $18 \mathrm{~h}$. In Table II we have hourly averages of relative humidity at nine stations These have in the main been reprinted from previously published averages for first-order observatories, but data from two new stations, Sealand and Cranwell, have been added to improve the geographical distribution. Table III contains hourly averages of vapour pressure at Kew and Eskdalemuir. This is followed by an appendix containing the standard values of the vapour pressure and moisture content in saturated air at all temperatures from $0^{\circ} \mathrm{F}$. to $120^{\circ} \mathrm{F}$. These are based on the determinations of Scheel and Heuse and are given to two places of decimals". In combination with the data contained in Table $I$, they afford the means of calculating average values of such quantities as saturationdeficit and dew-point, the methods of doing so being explained in the introduction.

The charts show the distribution of relative humidity and vapour pressure at $13 \mathrm{~h}$. over the British Isles in each month and the whole year. The scale, though small, is sufficient to display the general features of the geographical distribution, and to permit of the possibility of interpolating values for particular places with fair accuracy. The charts show that the distribution of mean relative humidity at midday is, as might be expected, complementary to that of mean maximum temperature, the lowest values being found in the inland areas where the afternoon temperature is high. In addition, there are clear indications of Föhn effects in winter months, patches of relatively dry air being located along the Great Glen, on the east coast of Scotland and along the Welsh border. The dry air during the night hours in the Great Glen results in Fort William having the lowest daily mean humidity of the nine stations for which hourly averages are given. Another interesting fact revealed by the new data is that at Eskdalemuir in the southern uplands of Scotland, the diurnal range of vapour pressure is substantially greater than at Kew in summer months. It is impossible in this article to enter upon any general discussion of the data, but it is clear that this publication contains sufficient information to meet the needs of most inquirers.

'Stacey, W. F., "Distribution of Relative Humidity in England and Wales", Quart. J. Roy. Met. Soc., 41, 45 (1915).

"The Book of Normals". M.O. 236. Sec. VI. "Normals of Relative Humidity". (London: H.M. Stationery Office, 1928.)

"Bilham, E. G., "The Climate of the British Isles" (Macmillan and Co., 1938).

- Scheel and Heuse, Ann. Phys., 1909 and 1910. 